\title{
Evaluation Model Analysis of Sports Instrument Influences on Class drill
}

\author{
1,a Zhu Xueqiang \\ ${ }^{1}$ Shandong Sport University, Jinan, ShanDong 250102,China \\ azxqzmx@163.com
}

Keywords: Sports instrument; class training; evaluation model; analytical hierarchy process

\begin{abstract}
This research, based on Abraham Harold Maslow's hierarchy of needs and the healthy definition of "WHO", analyzes relevant value indicates such as the fitness value, metal health value, entertainment value, the value of education, ornamental value and social value to grab a rough understanding that hand instruments are right in need of a specific time, which is of great significance to guide participation of instrument sports and physical development.
\end{abstract}

\section{Introduction}

Rapid economic and social development in China stimulates the general public to pay greater attention to health $[1,2,3]$. "Health first" and "lifetime sports" has become the main stream of new-ear sports activities. As there is an increasing number of sports, new requirements have emerged for sports instrument innovation. Apparently, traditional instruments cannot follow the new trend, thus, it is inevitable that we need to conduct innovation and reform of sports facilities [5]. Over the years, our sports teaching in national schools mainly refer to western modern sports, which cause problems of field and instrument allocation with greater focus on competitive sports. Despite of heavy investment, field and instruments are still restraint factors of college sports teaching. At present, many colleges have set up various new-type sports fields and gyms, meeting demands of college sports teaching and teaching evaluation temporarily. However, the utilization rate is not reaching the high in expectation and maintenance costs are relatively high, which leads to new issues related to wasting of resources.

This paper conducts analysis on the sports value of instruments by such methods as documentation, expert interview, Delphi method, field survey, mathematical statistics and logic analysis to establish the evaluation model analysis of sports instrument influences on class training. Then, expert feedback of the sports value and weight calculation of sports value of hand facilities concludes that instrument sports meet the demands of time with the fitness value, metal health value, entertainment value, the value of education, ornamental value and social value and student participation is important for physical sports and development.

\section{Sports Instrument and Teaching Guidance Evaluation}

Concept and Role of Sports Instrument: Sports instrument is a generic term referring to all the facilities, equipment and supplies in competitive sports and fitness exercise. As increasing awareness of health, popularization of sports, accelerated living process and constantly emerging sports produce a more obviously connection between sports facilities and activities. Players are requiring higher quality of sports instruments as they have realized instruments with good quality, stable performance and safety not only serves as a guarantee for fair and fierce competitions, but also the premise for cultivating sports interests and higher sports competence.

Sports exercise and body-building cannot be independent from material conditions, of which sports instrument is of great importance. The facilities enable players to enhance body coordination and flexibility, strengthen muscle and cultivate perseverance. With multiple cultivation and exercise, sports instrument plays a key role in physical activities.

Low Utilization Efficiency: As "risk-free" teaching ideas has been widely promoted in middle school sports teaching, quite a large number of teachers worry too much about accidents caused by 
sports instrument operating errors. Thus they always try to avoid sports teaching with any difficulty, risk or danger. What's more, during the teaching process, instrument is rarely used. Thus, in the teaching process in middle schools, a large amount of instrument is obsolete.

Single Sports Teaching Mode: Most sports teachers' teaching methods are only limited to fixed teaching modes, which means that they only pay attention to the outer nature of facilities rather than its potential use, leading waste of resources. Hurdles, for example, can be used as traditional hurdles, but also can be used as small football gates as well as the barriers of overstepping. Solid spheres can be thrown but also to be signals and barriers in nearly all the teaching and games. Elastic can also be used as cable machines to exercise students for arm strength and jumping. Sandbags, in addition to being played in games named "playing balls", "beating snails” and kicking, can be used for students to throw to see who can get the longest distance. Rational use of sports instrument is the recycled process of restricted resources as well as an effective way of saving sports resources.

\section{Evaluation Model of Instrument Sports}

Abraham Harold Maslow's hierarchy of needs states that human demands come out in the form of hierarchy and the order from low to high. The needs are physiological needs, security needs, social demand, demand to be respected and self-realization [7]. Players should establish relations with the team to become a member and find a sense of belonging. Good exercise style, various light instrument gymnastics and harmonious interaction and mutual assistance can obtain others' respect and appreciation. All the needs are summarized from perspectives of security needs, social needs and demand to be respected. After the first four demands are met, an individual have a sense of achievement. All the people have this kind of feeling. Based on the theory of Maslow's, it is close to reality, sports and the special case of real life. The demands can be met and the value can be realized. As shown in Figure 1, the writer establishes the evaluation system index of sports instrument named health value (A), self satisfaction value (B) and the interpersonal value (C).

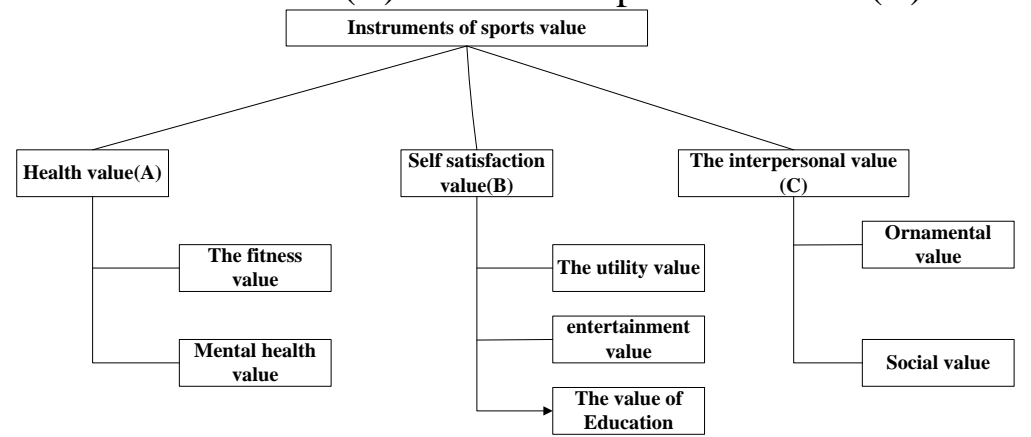

Figure 1 Evaluation Model Analysis of Sports Instrument Based on WHO Hierarchy Method

During the process of individual life and development, people usually use instrument to meet their demands. The value of hand instrument gymnastics is dependent on people. If there is no relation with people, there is no value for instruments. The value comes from practice as instrument is produced and developed from human needs. When we want to pay attention to health, the sports can meet more self-need. There are various categorized ways of instrument sports. In terms of influential objects, there are group value and individual value. In terms of influential levels, there are physical level, mental level and social level. Other standards also exist.

\section{Value Indicator Analysis of Instrument Sports}

Weight Coefficient of Instrument Sports Value Index: Instrument sports value mainly includes the fitness value, mental health value, the utility value, entertainment value, the value of education, ornamental value and social value. Reasonable index analysis standard is very important for sports value evaluation, and fuzzy analysis method is adopted to evaluate grade $\mathrm{D}=\{\mathrm{d} 1, \mathrm{~d} 2, \ldots, \mathrm{dn}\}$ and membership functions. This paper divides the value into four grades, mainly excellent, good, general, and worse $\}$, and summarizes corresponding threshold values $\{\mathrm{d} 1, \mathrm{~d} 2, \ldots \mathrm{Dn}\}$. Then according to the membership function for the threshold of contrast analysis, different indicators of evaluation 
grade are obtained. This article adopts the method of trapezoid distribution and half trapezoid distribution to set up membership function [7] and get membership function graph of the distribution of sports equipment training as shown in Figure 2. d1, d2,.., d5 are the threshold values under different level, c1 ,c2,... , c5, are respectively midpoints in (d1, d2), [d2 and d3], [d3, d4], [d4, d5] . According to the above methods, the corresponding threshold values upon different level.

Confirmation of Index Weight: The weight matrix is set up based on the vague gradation method with the hypothesis of $n$ indicators. $A=\{$ Aij $\} n * n$ is a symmetric matrix, in which aij represents the ratio of importance for $\mathrm{I}$ to $\mathrm{j}$ as shown in Table 1.

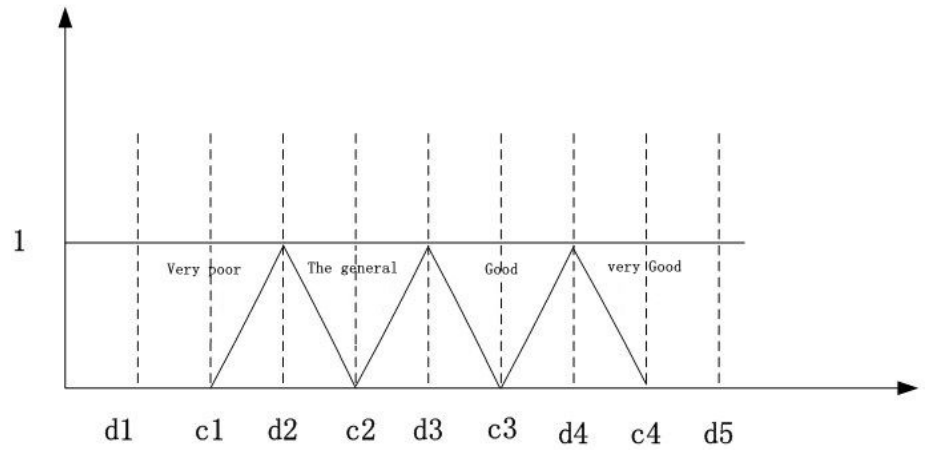

Figure 2 Subordinating Degree Function of Value Distribution of Sports Instrument

Table 1 Standards of Weight

\begin{tabular}{|l|l|}
\hline Importance of Weight & Vague Gradation \\
\hline $\mathrm{i}$ is important as $\mathrm{j}$ & 1 \\
\hline i is little important than $\mathrm{j}$ & 3 \\
\hline i is quite important than $\mathrm{j}$ & 5 \\
\hline $\mathrm{i}$ is much important than $\mathrm{j}$ & 7 \\
\hline i is more important than $\mathrm{j}$ & $2,4,6$ \\
\hline
\end{tabular}

After the comparative analysis of weight, the writer generalized above matrix to get weight value. This paper takes root method to test and the specific calculation is as follows: the product ofeach row from the matrix is calculated to conduct $n$ root. The weight value can be obtained from generalization.

Each index is after the index threshold and the corresponding index weight value can be calculated. This paper uses A grade standard and the corresponding weighted average approach to complete the evaluation of A target layer. The specific calculation formula is as follows:

$\mathrm{Hi}=\sum_{=\min \left\{1, \mathrm{R}_{i} W_{i}\right\}}^{\sum \mathrm{R}_{i} W_{i}}$

$\mathrm{Hi}$ refers to the general target of sports instrument value for sports class. $\mathrm{Ri}$ is an indicator of the corresponding evaluation level threshold. Wi is an indicator relative to the weight of A target layer. By the comparative standards and calculation can the writer obtain the value evaluation standard.

\section{Analysis of Evaluation Results}

Hand instrument gymnastics value mainly includes the fitness value (0.2403), mental health value (0.1828), the utility value (0.1591), entertainment value (0.1376), value of education (0.1162), ornamental value $(0.1032)$ and social value $(0.0968)$. The 7 values are in a order according to the value as shown in Figure 3.

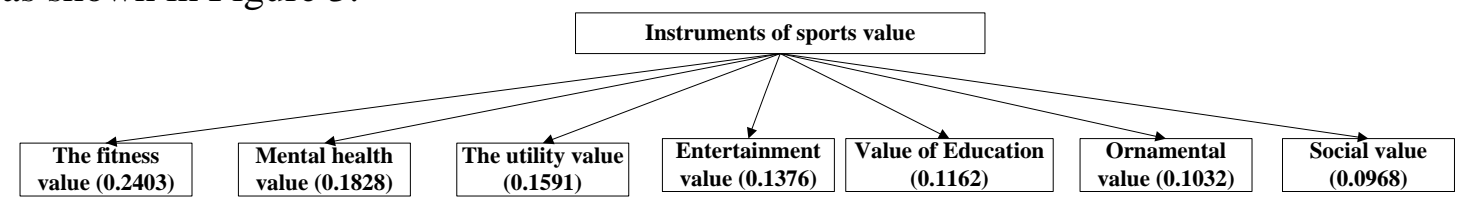

Body improvement value is slightly higher than that of physical quality value and shape value. Body improvement value refers to the effect of light instrument gymnastics on people through participation in sports system and body function, including improving value of the sports system function (0.3445), value of the function of human body (0.4222) and the value of metabolism 
(0.2333). The second one is more prominent. Physical quality development refers to the improvement of all the human body functions in hand instrument gymnastics, including improving flexibility value (0.3491), sensitive value (0.3964) and coordination value (0.2545). According the study, all the human functions are closely related to each other and the improvement of coordination is based on improving flexiblity and sensitivity.

Mental health cultivation value (0.6071) and maintenance value (0.3929) both exist and the first one is more important. The first term refers to the function of obtain a life with health, peace and possessiveness including is to point to help people to the healthy and stable state of mind to face life with optimism, including emotional stability, good mood (0.3939), reducing anxiety, eliminating sorrow (0.3455) and coordinative behavior (0.2606), of which the first two are more important. Maintenance value refers to the mood to fit all kinds of discomfort and get along with people including the establishment of good social relationship (0.3962) and social adaptability (0.6038). The latter one is more prominent.

The utility value contains the applicable value (0.5897) and the development ability value (0.4103), the applicable value is higher. Applicable value refers to the practical characteristic that hand instrument gymnastics is easy to do and learn, which can meet various demands and enable players to get efficient exercise including comprehensive value (0.4118) and easy value of (0.5881). The latter one is higher. Development ability value refers that the light instrument gymnastics, through practice, can make people become sensitive and coordinative with ability of running, jumping and throwing, including living ability (0.6018) and surviving ability(0.3982). The first one is higher.

There are value of lifetime sports consciousness (0.5776) and value of sports spirit cultivation (0.4224). The first one refers to training sports ability and consciousness by hand instrument, including the value of physical education (0.3750) and the value of sports intelligence education (0.6250), the latter is higher. The value of sports spirit cultivation means that people can face challenges in life with the spirit including spirit of solidarity and collaboration (0.5439) and competition consciousness $(0.4561)$, of which the first one is more prominent.

The value of promoting self-cultivation (0.3613) and communication value (0.6387) also exist, of which the latter one is more important. The fist one means during the communication process of hand instrument sports, self-quality and cultivation can be improved, including standard behavior value (0.5545) and the moral value (0.4455), the latter one is more important. The communication value refers to exchanges and trust produced from the process of hand instrument sports and ways of communication and living philosophy, including the value of the interactive learning (0.4528) and the value of communication awareness (0.5472), of which the latter one is more important.

\section{Conclusions and Policy Significance}

Differences in quality of sports equipment will affect the students' mastering of sports, leading tasks that are not ideal, the teaching mood and normal effects of class teaching. Therefore, according to characteristics of the sports option classes, it is very important to choose different sports equipment, which is one of the premises to ensure the quality of the elective course teaching. Based on Maslow's hierarchy of needs and "WHO" health definition, this paper analyzes the value of hand sports instrument including fitness value, mental health value, the utility value, entertainment value, value of education, ornamental value and social value. The values meet the demands of people in a special period, representing the general guideline of instrument development and important for participation of hand instrument sports and physical development.

\section{References}

[1] Tang Jingang. Innovation and applied research of sports instrument [J].China Education Technical Equipment,2012,23(3):54-56.

[2] Wang Kunxia . Exploration and application of inner physical sports instrument [J]. Early Phase Education,2010(7):59. 
[3] Guo Yang. Value of self-made sports instrument on sports exercises outdoor [J]. Primary Age ,2010(10):108.

[4] Hu Xiaoming, Shi Long. Physical Axiology [M].Chengdu: Sichuan Science and Technology Press,2008,1.

[5] Deng Wencai. Cognition of Physical Value under happiness [J]. Academic Paper of Physical Education,2005,12 (3) : 34-37.

[6] Chen Huasheng. Influences of sports instrument on class training [J]. Journal of China's Science and Innovation,2011,30(8): 54.

[7] Ming Yu. Empirical research of Sino-American sports instrument patent competition in the international world [J]. Journal of Beijing University of Physical Education,2013,36(4): 18-23.

[8] Jin Zhuo. Education of Educational value sports instrument in educational activities in kindgardens. [J]. Journal of reading and writing,2014,11 (4) : 243.

[9] Li Gengquan. Evaluation research of sports value in harmonious society [J]. Journal of Beijing University of Physical Education, 2012,35 (1) : 13-15. 